\title{
Evaluating Quality of Life of Parents Having a Child with Disability
}

*Rita Kumari Ban ${ }^{1}$, Iswari Luitel ${ }^{2}$, Kalpana Regmi ${ }^{1}$

${ }^{1}$ Nepalese Army Institute of Health Sciences, Sanobharyang, Kathmandu, Nepal

${ }^{2}$ Om Health Campus, Kathmandu, Nepal

\section{*Corresponding Author:}

Rita Kumari Ban, Lecturer; E-mail: rusatrita37@gmail.com +9779851233214

\begin{abstract}
:
Introduction: Disability is the condition of difficulty in carrying out daily activities normally and in taking part in social life due to problems in parts of the body and the physical system Children with disabilities are one of the most marginalized and excluded groups in society. Facing daily discrimination in the form of negative attitudes, Estimates suggest that there are at least 93 million children with disabilities in the world, but numbers could be much higher

Method: A descriptive analytical research design was used to identify the quality of life of parents/caretakers having a child with disability/ies in Illam district. Systematic random sampling was used and collected data from 244 participants. World Health Organization Quality of Life-Brief (WHOQOL-BREF) Questionnaire was adopted Association between the socio-demographic variables and four domains of WHOQOL was determined using one way ANOVA. In the end, multiple linear regression analysis was performed to find the predictors of domains of WHOQOL and to control the confounding effect.

Results: The quality of parents having a child with disability have good quality of life in social relationship mean 15.6 \pm 1 .3.The physical domain is weakly correlated with the social domain. There is a moderate positive correlation between psychosocial and the social domains. Cognitive disability mean score was highest on social domain that is 14.91and lowest on the physical domain (13.87).

Conclusion: To improve quality life of parents, health care and welfare professionals should focus on particular people with higher age group, disadvantaged and marginalized groups illiterate, those who are unmarried, divorced or separated and those engaged in agriculture and carry out interventions aimed at improving their quality of life.
\end{abstract}

Key words: Parents /care taker, Quality of life, Children with disability

\begin{tabular}{|l|l|l|}
\hline \multicolumn{2}{|c|}{ Access this article Online } & Article Info. \\
\hline Quick Response Code & Website: & How to cite this article in Vancouver Style? \\
\hline & www.jkahs.org.np & Ban R, Luietal I, Regmi K. Evaluating \\
Quality of Life of Parents Having a Child \\
with Disability. Karnali Academy of Health \\
Sciences 2020;3(1):1-10
\end{tabular}




\section{INTRODUCTION}

Disability can be stated as restriction or loss of ability in performing an activity in appropriate manner or way due to impairment in body function or structure. Such condition leads an individual in activity limitation and difficulty in executing a task or action. ${ }^{1}$ Disability also creates difficulty in functioning daily activities normally. ${ }^{2}$ A child with a disability means a child who has mental or physical inability either congenital , caused by injury or because of any diseases. Such disabilities can be like mental retardation, hearing impairment, speech or language impairment, specific learning disability or deaf-blindness an individual with disability. ${ }^{3}$

More than one billion people live with a disability. About 110 million people (2.2\% of the global population) have very severe functional difficulties. Among them, $80 \%$ of people with disabilities live in developing countries. ${ }^{4}$ Children aged between $0-14$ years experiencing "moderate or severe disability” at 93 million (5.1\%) and 13 million (0.7\%) of children experiencing severe difficulties because of various disability. ${ }^{5}$ In 2005, UNICEF estimated that the number of children with disabilities under age 18 at 150 million. Recent study findings conducted in developing countries reports child disability prevalence ranges from $0.4 \%$ to $12.7 \%$. ${ }^{1}$ The implications of caring for a child with disability/ies are considerable and have profound effects on the entire family who may be parents, siblings, and other extended family members. Because of dependency, in providing high-quality care required by a child with long-term functional limitations can influence the health and quality of life (QOL) among the caregivers. ${ }^{6}$

Children's disabilities and distresses may burden to their family members, especially their parents, who are their long-term care providers. This may affect their parents' quality of life as they need to spend most of their time in taking care of such child. So, such parents are unable to engage in other activities and diminish their social life which negatively affects their quality of life. ${ }^{7}$

\section{MATERIALS AND METHOD}

A descriptive exploratory research design was used to identify the quality of life of parents/caretakers having a child with disability/ies. The study was conducted in Illam district. The Study population included parents or caretakers having a child with disability/ies. Systematic random sampling was used and collected data from 244 participants. World Health Organization Quality of Life-Brief (WHOQOL-BREF) Questionnaire was adopted and basic modification was done according to research objectives. For the use of the tools in the Nepalese context, forward translation (from English to Nepali) and backward translation (from Nepali to English) was done. After the submission of formal written letter from the concerned authority Institutional review 
committee of the Nepalese Army Institute of Health Sciences provided ethical approval for the study. One day orientation about the use of the tool was given to the enumerators. Data was collected from 2076/04/15 to 2076/6/15. All the respondents were interviewed by face to face interview method by using semistructured interview schedule after taking written consent. After complete checked of

\section{RESULTS}

Among the participants, more than three-fifths (63.6\%) of the participants were in the age group of 31 to 50 years with age ranging from 14 to 84 years. The majority (64.3\%) of the participants were Janajati, followed by $27 \%$ of Bramhin/Chhetri and 8.2\% Dalit participants. Regarding sex, two-thirds (66.4\%) of the participants were female. The majority (90.6\%) of the participants were married as regard to their marital status. More than one fourth (31.1\%) of the participants were illiterate or had informal education whereas more than one third (35.7\%) had completed secondary education. Agriculture was the main occupation of the participants (697\%). Among the participants, about two-thirds (65.6\%) were from the nuclear family (table 1).

Table 1: Socio-demographic characteristics of the participants

\begin{tabular}{|l|l|l|}
\hline Characteristics $(n=244)$ & No & Percent \\
\hline Age & & \\
\hline S30 years & 42 & 17.2 \\
\hline 31 to 40 years & 88 & 36.1 \\
\hline 41 to 50 years & 67 & 27.5 \\
\hline > 50 years & 47 & 19.3 \\
\hline
\end{tabular}

collected data, it was coded, classified and entered through SPSS version 20 for data analysis. Association between the sociodemographic variables and four domains of WHOQOL was determined using one way ANOVA and multiple linear regression analysis was performed to find the predictors of domains of WHOQOL and to control the confounding effect.

\begin{tabular}{|l|l|l|}
\hline Range (14-84) years & & \\
\hline Ethnicity* & 20 & 8.2 \\
\hline Dalit & 157 & 64.3 \\
\hline Janajati & 66 & 27.0 \\
\hline Brahmin/Chhetri & & \\
\hline Sex & 162 & 66.4 \\
\hline Female & 82 & 33.6 \\
\hline Male & & \\
\hline Marital status & 14 & 5.7 \\
\hline Unmarried & 221 & 90.6 \\
\hline Married & 2 & 0.8 \\
\hline Separated & 7 & 2.9 \\
\hline Widow & & \\
\hline Education & 76 & 31.1 \\
\hline $\begin{array}{l}\text { Illiterate or informal } \\
\text { education }\end{array}$ & & \\
\hline Primary education & 68 & 27.9 \\
\hline Secondary education & 87 & 35.7 \\
\hline Higher secondary and above & 13 & 5.3 \\
\hline Occupation & & \\
\hline Agriculture & 170 & 69.7 \\
\hline Business/labor/GO/others & 28 & 11.5 \\
\hline $\begin{array}{l}\text { Student/Housewife/Not } \\
\text { earning }\end{array}$ & 46 & 18.9 \\
\hline Type of family & & \\
\hline Nuclear & 160 & 65.6 \\
\hline Joint & 34.4 \\
\hline ind other (0.4\%) & \\
\hline
\end{tabular}

*include others $(0.4 \%)$

Table 2: WHOQOL-BREF domains of the study participants

\begin{tabular}{lrrc}
$\begin{array}{l}\text { Domains } \\
\text { Physical } \\
\text { health }\end{array}$ & 9.1 & 16.6 & $13.6 \pm 1.4$ \\
$\begin{array}{l}\text { Psychological } \\
\begin{array}{l}\text { Social } \\
\text { relations }\end{array}\end{array}$ & 6.7 & 18.7 & $12.6 \pm 1.8$ \\
\begin{tabular}{l} 
Environmental \\
\hline
\end{tabular} & 6.0 & 20.0 & $15.6 \pm 1.3$ \\
& 6.5 & 16.0 & $11.9 \pm 1.7$ \\
\hline
\end{tabular}


Abbreviation: WHOQOL-BREF: World Health Organization Quality of Life-BREF

As presented in Table 2, the mean scores for physical, psychological, social relationships and environmental domains are 13.6 (SD=1.4), $12.6 \quad(\mathrm{SD}=1.8), \quad 15.6 \quad(\mathrm{SD}=1.3)$ and 11.9 $(\mathrm{SD}=1.7)$ respectively.

Table 3: Mean scores of quality of life domains among different subgroups (transformed scores 4-20)

\begin{tabular}{|c|c|c|c|c|}
\hline \multicolumn{2}{|l|}{ Characteristics } & \multicolumn{3}{|c|}{ Domains of quality of Life (mean \pm SD) } \\
\hline Age & Physical & Psychological & Social & Environmental \\
\hline$\leq 30$ years & $13.8 \pm 1.2$ & $12.7 \pm 1.5$ & $15.6 \pm 1.3$ & $12.5 \pm 1.2$ \\
\hline 31 to 40 years & $14.0 \pm 1.2$ & $13.2 \pm 1.6$ & $15.8 \pm 1.5$ & $12.1 \pm 1.7$ \\
\hline 41 to 50 years & $13.5 \pm 1.3$ & $12.5 \pm 1.9$ & $15.6 \pm 1.2$ & $11.8 \pm 1.6$ \\
\hline$>50$ years & $12.8 \pm 1.5$ & $11.8 \pm 1.7$ & $15.1 \pm 1.2$ & $11.3 \pm 1.6$ \\
\hline P value & $<0.001$ & $<0.001$ & 0.078 & $<0.05$ \\
\hline \multicolumn{5}{|l|}{ Ethnicity } \\
\hline Dalit & $13.8 \pm 1.1$ & $12.5 \pm 1.3$ & $15.4 \pm 2.0$ & $11.7 \pm 1.2$ \\
\hline Janajati & $13.5 \pm 1.3$ & $12.4 \pm 1.6$ & $15.6 \pm 1.1$ & $11.9 \pm 1.6$ \\
\hline Brahmin/Chhetri & $13.7 \pm 1.5$ & $13.2 \pm 2.0$ & $15.6 \pm 1.5$ & $12.2 \pm 1.9$ \\
\hline P value & 0.606 & $<0.05$ & 0.924 & 0.181 \\
\hline \multicolumn{5}{|l|}{ Sex } \\
\hline Female & $13.6 \pm 1.5$ & $12.6 \pm 1.8$ & $15.5 \pm 1.2$ & $11.9 \pm 1.8$ \\
\hline Male & $13.6 \pm 1.1$ & $12.6 \pm 1.7$ & $15.7 \pm 1.5$ & $11.9 \pm 1.5$ \\
\hline$P$ value & 0.931 & 0.906 & 0.476 & 0.933 \\
\hline \multicolumn{5}{|l|}{ Marital status } \\
\hline Unmarried & $13.4 \pm 1.4$ & $12.7 \pm 2.1$ & $14.9 \pm 1.4$ & $12.5 \pm 1.7$ \\
\hline Married & $13.6 \pm 1.3$ & $12.6 \pm 1.7$ & $15.7 \pm 1.2$ & $11.9 \pm 1.6$ \\
\hline Separated & $14.0 \pm 0.4$ & $12.0 \pm 0.9$ & $12.0 \pm 5.7$ & $11.0 \pm 2.8$ \\
\hline Widow & $12.7 \pm 1.6$ & $12.6 \pm 1.8$ & $14.5 \pm 1.2$ & $11.2 \pm 2.3$ \\
\hline P value & 0.360 & 0.960 & $<0.001$ & 0.321 \\
\hline \multicolumn{5}{|l|}{ Education } \\
\hline $\begin{array}{l}\text { Illiterate or informal } \\
\text { education }\end{array}$ & $13.2 \pm 1.5$ & $12.0 \pm 1.7$ & $15.2 \pm 1.5$ & $11.2 \pm 1.5$ \\
\hline Primary education & $13.6 \pm 1.3$ & $12.6 \pm 1.8$ & $15.8 \pm 1.2$ & $12.0 \pm 1.6$ \\
\hline Secondary education & $13.9 \pm 1.2$ & $13.1 \pm 1.7$ & $15.7 \pm 1.3$ & $12.4 \pm 1.7$ \\
\hline $\begin{array}{l}\text { Higher secondary and } \\
\text { above }\end{array}$ & $13.7 \pm 1.3$ & $13.1 \pm 1.1$ & $15.4 \pm 1.0$ & $12.6 \pm 1.7$ \\
\hline P value & $<0.05$ & $<0.001$ & $<0.05$ & $<0.001$ \\
\hline \multicolumn{5}{|l|}{ Occupation } \\
\hline Agriculture & $13.5 \pm 1.3$ & $12.5 \pm 1.8$ & $15.7 \pm 1.2$ & $11.8 \pm 1.6$ \\
\hline Business/labor/GO/others & $13.7 \pm 1.3$ & $13.0 \pm 1.9$ & $15.0 \pm 1.9$ & $12.4 \pm 1.9$ \\
\hline
\end{tabular}




\begin{tabular}{|l|l|l|l|l|}
\hline $\begin{array}{l}\text { student/housewife/not } \\
\text { earning }\end{array}$ & $13.8 \pm 1.5$ & $12.9 \pm 1.2$ & $15.4 \pm 1.4$ & $12.0 \pm 1.6$ \\
\hline P value & 0.347 & 0.196 & $<0.05$ & 0.225 \\
\hline Type of family & & & & \\
\hline Nuclear & $13.6 \pm 1.4$ & $12.7 \pm 1.7$ & $15.6 \pm 1.4$ & $11.8 \pm 1.7$ \\
\hline Joint & $13.6 \pm 1.3$ & $12.6 \pm 1.8$ & $15.5 \pm 1.2$ & $12.1 \pm 1.6$ \\
\hline P value & 0.692 & 0.638 & 0.770 & 0.239 \\
\hline
\end{tabular}

The mean score of four domains of WHOQOL-BREF according to age, ethnicity, sex, marital status, occupation and type of family are presented in Table 3. Mean score of physical, psychological and social domains was higher for parents/caretakers of age group 31 to 40 years but higher mean score of environmental domain was observed in parents less than or equal to 30 years of age. For ethnicity, higher mean score of all domains was observed among Brahmin/Chhetri. Mean scores of physical and psychological domains was lower among Janjatis whereas for social and environmental domains, the score was lower among Dalit. Regarding sex, the mean scores were almost equal among male and female.

In regard to their marital status and occupation, there was fluctuation in the mean scores across domains. The mean score of psychological and environmental domains were higher for unmarried parents/caretakers while the mean scores of physical and social relationships were higher for separated and married. Regarding their education, the mean score of physical domain was higher for parents/caretakers having completed secondary education. Similarly, mean score of psychological domain was higher and equal for parents/caretakers having their secondary and higher secondary and above education completed while the score of environmental domain was higher among parents/caretakers who have completed higher secondary and above education.

However, mean score of social domain was higher among those parents/caretakers who have completed primary education. Mean score of physical domain was higher for students, housewife and those not engaged in any occupation and lower for parents/caretaker who was engaged in agriculture. For psychological and environmental domains, the mean score was higher for those who were involved in business/labor/government organizations and lower for parents/caretaker involved in agriculture. Mean score of social relationships was higher for parents/caretaker engaged in agriculture and lower for those who were involved in business/labor/government organizations. The mean scores of physical, psychological and social relationships were almost similar for nuclear and joint families while the score was higher in parents/caretaker 
living in joint family for environmental

domain.

Table 4: Correlation between four domains of WHOQOL-BREF

\begin{tabular}{|l|l|r|r|r|r|}
\hline Domains & & Physical & Psychological & Social & Environmental \\
\hline Physical & Pearson Correlation & 1 & 0.432 & 0.041 & 0.336 \\
\cline { 2 - 5 } & Sig. (2-tailed) & & $<0.001$ & 0.520 & $<0.001$ \\
\hline \multirow{2}{*}{ Psychological } & Pearson Correlation & & 1 & 0.133 & 0.517 \\
\cline { 2 - 5 } & Sig. (2-tailed) & & $<0.05$ & $<0.001$ \\
\hline \multirow{2}{*}{ Environ } & Pearson Correlation & & & 1 & 0.125 \\
& Sig. (2-tailed) & & & & 0.051 \\
\hline & Pearson Correlation & & & & \\
\hline
\end{tabular}

Correlation between four domains of WHOQOL-BREF was presented in table 3. Among the four domains of WHOQOL-BREF, three domains namely physical, psychological and environmental were significantly and positively correlated with low to high relationships ( $r=0.336-0.517$, $p$ value $<0.001)$. However social relationship domain was only found to be correlated with psychological domain with low relationship $(r=0.133$, $p$ value $<0.05$ ).

Table 5: Multiple linear regression analysis of factors associated with different domains of WHOQOL

\begin{tabular}{|c|c|c|c|c|c|c|}
\hline \multirow{2}{*}{\multicolumn{2}{|c|}{ WHOQOL domains }} & \multicolumn{2}{|c|}{$\begin{array}{l}\text { Unstandardized } \\
\text { Coefficients }\end{array}$} & \multirow{2}{*}{$\begin{array}{c}\text { Standardized } \\
\text { Coefficients } \\
\text { Beta }\end{array}$} & \multirow[t]{2}{*}{$\mathbf{t}$} & \multirow[t]{2}{*}{ p value } \\
\hline & & Beta & Std. Error & & & \\
\hline Physical & Age & 0.589 & 0.214 & 0.202 & 2.752 & 0.006 \\
\hline \multirow[t]{2}{*}{ Psychological } & Ethnicity & 0.790 & 0.246 & 0.202 & 3.219 & 0.001 \\
\hline & Education & 0.665 & 0.266 & 0.177 & 2.501 & 0.013 \\
\hline \multirow[t]{2}{*}{ Social } & Marital status & 1.185 & 0.275 & 0.263 & 4.315 & $<0.001$ \\
\hline & Occupation & -0.472 & 0.176 & -0.165 & -2.680 & 0.008 \\
\hline Environmental & Education & 0.966 & 0.258 & 0.267 & 3.749 & $<0.001$ \\
\hline
\end{tabular}

Table 5 demonstrated the result of the final multiple linear regression model. Variable significantly associated with the physical domain of quality of life included: age was positively associated with QOL score with each unit change would lead to a 0.59 unit increment in the QOL score. The psychological domain was significantly and positively associated with the ethnicity of parents/caretakers, Brahmin/Chhetri was 
found to have 0.79 units more scores as compared to other ethnic groups. The psychological score was 0.67 units more among educated parents/caretakers as compared to those who were illiterate or had formal education. Similarly, variables significantly associated with the social relationship domain of quality of life included: marital status and occupation. The social relationship score increased by 1.19 units among married participants as compared to others. Occupation (agriculture) was negatively associated with the QOL scores with each unit change would lead to a 0.47 unit reduction in the QOL score. The educational level of parents/caretakers was significantly and positively associated with the environmental domain of quality of life. The score of QOL was found to increase by 0.97 units among educated parents compared to those who are illiterate or had formal education.

Table 6 Quality Life of Parents having a child With Disability Depending on the Type of Disability Variable

\begin{tabular}{|c|c|c|c|c|c|}
\hline \multirow[t]{2}{*}{$\begin{array}{l}\text { Type of } \\
\text { disability }\end{array}$} & Frequency & $\begin{array}{l}\text { Physical } \\
\text { Domain }\end{array}$ & Psychol. Domain & Social Domain & Environmental Domain \\
\hline & & Mean & Mean & Mean & Mean \\
\hline Physical & 140 & 13.50 & 12.83 & 15.61 & 12.10 \\
\hline Mental & 15 & 13.83 & 12.18 & 16.09 & 12.13 \\
\hline Cognitive & 22 & 13.87 & 12.48 & 14.91 & 11.82 \\
\hline Autism & 10 & 13.66 & 12.00 & 16.00 & 11.70 \\
\hline Multiple & 57 & 13.57 & 12.42 & 15.53 & 11.54 \\
\hline Total & 244 & 13.58 & 12.63 & 15.57 & 11.93 \\
\hline
\end{tabular}

Table 6 revealed that according to the Physical disability mean score of the physical domain was (13.5) and the environment was (12.10). Mental disability means the score was highest on the social domain (16.09) and lowest in environmental (12.13). Cognitive disability means the score was highest on the social domain (14.91) and lowest on the physical domain (13.87). The autism disability means the score was highest on the social domain (16.00) and lowest in the environmental domain (11.70). Multiple disabilities mean score was highest on the physical domain (13.57) and lowest on the environmental domain.

\section{DISCUSSION}

Socio- demographic characteristics showed that (63.6\%) of the participants were in the age group of 31 to 50 years with age ranging from 14 to 84 years. The majority (64.3\%) of the participants were Janjati, followed by $27 \%$ of Brahmin/Chhetri and 8.2\% Dalit participants. More than one fourth (31.1\%) of the participants were illiterate or had informal education. The mean scores for physical, psychological, social relationships and environmental domains are 13.6 ( $\mathrm{SD}=1.4)$, $12.6(\mathrm{SD}=1.8), 15.6 \quad(\mathrm{SD}=1.3)$ and 11.9 $(\mathrm{SD}=1.7)$ respectively. The mean physical, psychological and environmental domains of quality of life is significant at $\mathrm{p}<0.05$ in the 
different age group. In contrast to that, the social domain of quality of life is not significant. The mean Psychological domain of quality of life is significant at $\mathrm{p}<0.05$ level with different ethnic groups and not significant with other domain like physical, the social and environmental domain.

All four (physical, psychosocial, social and environmental) domains are significant at $\mathrm{p}<0.05$ level according to educational status. It can be concluded, education likely to determine the quality of life of parents who has children with disability. There is a positive correlation between physical, psychological and environmental However, the physical domain is weakly correlated with the social domain. There is a moderate positive correlation between psychosocial social domains which is significant at the 0.05 level. However, the social and environmental domain is weakly correlated. According to types of disability, Physical disability means score highest on physical domain 13.5 mental disabilities mean score was highest on Social domain 16.09. Cognitive disability means the score was highest on the social domain that is 14.91. The autism disability means the score was highest on Social domain 16.00. Multiple disabilities mean score was highest on physical domain 13.57.

In the present study, the caregiver gained the highest scores on the social aspect 15.6
$(\mathrm{SD}=1.3)$ and lowest in the environmental 11.9 $(\mathrm{SD}=1.7)$ domain. In contrast with the present findings conducted in Iran among 70 parents having Down syndrome, children showed that the highest scores on the physical aspect. ${ }^{8}$ It may be due to the early identification of problems and appropriate intervention. Similarly, another study conducted in Saudi Arabia among families having children with disabilities $(n=306)$ was also contrasted with the present findings where Environment domain had the highest score (SD=14.21) and the Spiritual domain had the lowest score ( $S D=4.72) .{ }^{9}$ It may be due to the quality of life of parents having a child with disability depending on the type of a disability variable. In the present study, the parents having a child with Cognitive disability mean score was highest on the social domain (14.91) and lowest on the physical domain (13.87) whereas autism disabilities mean score was highest on Social domain (16.00) and lowest in the environmental domain (11.70).

The study conducted in New Delhi, India with 60 parents having children of learning and autistic disability result findings contrasted with the present findings. Mothers of children with specific learning disabilities was a better quality of life in the physical domain and mother having children with autistic disorders were most likely experiencing poor quality of life in the physical domain. ${ }^{10}$ It may be due to different childhood conditions and their 
different effect as a consequence that can interfere parents quality of life ${ }^{20}$. In the present study, it has been found that the physical domain is weakly correlated with the social domain. There is a moderate positive correlation between psychosocial and social domains However; the social and environmental domain is weakly correlated. It means a change in one domain from one value to the other domain will also change in its corresponding to change in the domain.

\section{CONLCUSIONS}

The Quality of life (QoL) of parents having children with disability was highest for social domain and lowest for environmental domain. The physical, psychosocial and environmental domain of QoL had statistically significant positive correlation. Likewise, age, ethnicity, marital status, education and occupation were found to have statistical significance with one

\section{REFERENCES}

1. WHO. World report on disability. Geneva: WHO 2011. [Accessed 6 Aug2018]. Available from :

https://www.who.int/disabilities/world_report/ $\underline{2011}$

2. Government of Nepal. Definition and classification of disability in Nepal. Kathmandu, Nepal Government, 2006. [Accessed 20 Aug2018]. Available from: http://www.lawcommission.gov.np

3. Knoblauch BS. IDEA's Definition of Disabilities. ERIC Digest E 560 .[Accessed 2 sep.2018] Available from: https://files.eric.ed.gov

4. Thapaliya MP. A report on disability in Nepal. [Accessed 21 sep.2018]. Available from: https://www.australianhimalayanfoundation.or g.au/wp-content or more domains and were the predictors of QoL of the parents/caretakers having a child with a disability.

We recommend that health care and welfare professionals should focus in particular on people with a higher age group, disadvantaged and marginalized groups, illiterate, those who are unmarried, divorced or separated and those engaged in agriculture and carry out interventions aimed at improving their quality of life

\section{Acknowledgment}

Researchers are highly indebted to all staff of Karuna Foundation Nepal for grants to carry out this study. The researchers are extremely grateful to all respondents for their kind cooperation and participation in this study. We acknowledge the institutional ethical review committee of the Nepalese Army Institute of Health Sciences for providing ethical clearance for this study.

5. Greenstein C, Lowell A, Thomas D. Communication and context are important to Indigenous children with physical disability and their carers at a community based physiotherapy service: a qualitative study. Physiotherapy 2016; 62:42-47.

Google Scholar $|\underline{\text { CrossRef }}| \underline{\text { Full Text }}$

6. Davis E, Shelly A, Waters E, Boyd R, Cook $\mathrm{K}$, Davern M. The impact of caring for a child with cerebral palsy: quality of life for mothers and fathers. Child Care Health Dev 2009; 36(1): 63-73.

Google Scholar | CrossRef | Full Text

7. World Health Organization. The World Bank. World report on disability. 2011. WHO

Library Cataloguing-in-Publication Data. 2011.

Google Scholar $\mid \underline{\text { Full Text }}$

8. Abbasi S, Sajedi F, Hemmati S, Najafi Fard T, Azadchehr MJ, Poursadoghi A. Evaluation of quality of life in mothers of children with 
Down syndrome. Practice in Clinical Psychology. 2016 Apr 10;4(2):81-8. Google Scholar | CrossRef | Full Text

9. Abu Hawwash RM, Haimour AI. Evaluating Quality Of Life of parents having a child with disability. International Interdisciplinary Journal of Education. 2012 Mar;1(2):37-43 . [Accessed 6 Jan.2019]. Available from: Google Scholar | Full Text

10. Khan MF, Humtsoe MK. Quality of life of mothers having children with autistic spectrum disorders and learning disabilities. Journal of Physical Education Research. 2016; 3(1):38-46

Google Scholar | Full Text

11. Whoqol Group. The World Health Organization quality of life assessment (WHOQOL): position paper from the World Health Organization. Social science \& medicine. 1995 Nov 1; 41 (10):1403-9. Link

12. Mol TI, Van Brakel W, Schreurs M. Children with Disability in Nepal: New Hope through CBR? Disability, CBR \& Inclusive Development. 2014 May 19; 25(1):5-20. Google Scholar | CrossRef | Full Text

13. Alenazi DS, Hammad SM, Mohamed AE. Effect of autism on parental quality of life in Arar city, Saudi Arabia. Journal of Family and Community Medicine. 2020 Jan 1;27(1):15 Google Scholar | Full Text

14. Jespersen LN, Michelsen SI, TjørnhøjThomsen T, Svensson MK, Holstein BE, Due P. Living with a disability: a qualitative study of associations between social relations, social participation and quality of life. Disability and rehabilitation. 2019 May 22;41(11):1275-86. Google Scholar | PubMed | CrossRef

15. Wakimizu R, Yamaguchi K, Fujioka H. Family empowerment and quality of life of parents raising children with Developmental Disabilities in 78 Japanese families. International Journal of Nursing Sciences. 2017 Jan 10;4(1):38-45.

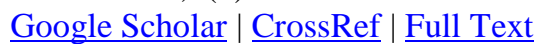

16. Juhásová A. Comparison of quality of life of families with children with disability and families with children without disability. Procedia-Social and Behavioral Sciences. 2015 Feb 12; 174:3378-84.

Full Text

17. Gomez IN, Gomez MG. Quality of life of parents of filipino children with special needs. Education Quarterly. 2013;71 (2).

Google Scholar | Full Text

18. Dardas LA, Ahmad MM. Quality of life among parents of children with autistic disorder: A sample from the Arab world. Research in Developmental Disabilities. 2014 Feb 28; 35(2):278-87. Google Scholar $\mid$ CrossRef $\mid$ Full Text

19. UNICEF. The state of the world's children: children with disabilities. UN; 2013.[Accessed 18 Mar.2019]. Full Text

20. Ganesh Amgain. Cool Parent Syndrome; Redefining Cool. Europasian Journal of Medical Sciences [Internet]. 2019.1(1):1-4. Google Scholar | Full Text 